\title{
IDENTIFICATION OF THE GEOLOGIC ORIGINS OF ARCHAEOLOGICAL ARTIFACTS: AN AUTOMATED METHOD OF Na and Mn NEUTRON ACTIVATION ANALYSIS
}

\author{
BY A. A. GORDUS, W. C. FINK* M. E. HILL*, J. C. PURDY* \\ and T. R. WILCOX* \\ Department of Chemistry, The University of Michigan, \\ Ann Arbor, Michigan 48104
}

\section{INTRODUCTION}

Similarities in the design and construction of archaeological artifacts frequently have served as a means of identifying the existence of contact and trade between prehistoric cultures. However, such evidence is not necessarily conclusive. Knowledge of the geologic origin of an archaeological artifact would provide direct evidence of a link between the geographic region in which the artifact was found and the geologic source area.

Locating the geologic origins of archaeological artifacts is a formidable task. It is first necessary to determine which elements vary markedly between geologic sites, but within a given geologic site exhibit only a small percentage variation. Then a comparison must be made between the percentage composition of these elements in the artifacts and in the source materials. In making the comparisons it is necessary to know the statistical range of compositions of these elements at the various geological sites; a large number of individual analyses are required. Although it may never be possible to state with absolute certainty that a particular artifact had a specific geologic origin, the greater the number of elements that showed correspondence, the more unlikely it would be that some unexamined geologic site was the true source of the material from which the artifact was constructed.

Neutron activation analysis is an ideal method of analysis to use in studies of this type. The method requires using samples which could be as small as a $\mathrm{mg}$ or less. It is possible to automate steps in the procedure to permit handling thousands of samples per year. If the resultant radioactivity is of short half-lives it is possible to re-irradiate the samples after the activity has decayed and perform repeat analyses on the samples. Unlike X-ray fluorescence which permits examination of only the surfaces of objects, the penetration of neutrons through a sample results in the activation of all parts of the object.

However, in spite of these advantages, very little has been done in applying neutron activation analysis to archaeological problems. A few workers have examined gold and silver coins and other objects of metal. Others have irradiated various types of sherds. The most complete studies are those of Sayre, et. al. But the exhaustive studies necessary for proper statistical evaluations of the data have not been undertaken. In collaboration with Prof. James B. Griffin, Director of the Museum of Anthropology at The University of Michigan, we have begun a systematic evaluation of various artifacts related principally to the prehistory of North America. The majority of these samples are obsidian projectile points and the neutron activation procedure which we have developed for the analysis and geologic identification of the objects forms the basis of this paper.

*Undergraduate Honors Research Participants 
When obsidian is irradiated with thermal neutrons for a few seconds or minutes, the sample initially exhibits mainly $2.3 \mathrm{~min}$ half-life ${ }^{28} \mathrm{Al}$ activity. Knowledge of the aluminum content of obsidian is not particularly useful in identifying the geologic source of the sample since the aluminum content of obsidian does not vary markedly between sources. However, almost all of the observed radioactivity during the period 2-24 hours following the neutron irradiation is due to ${ }^{24} \mathrm{Na}$ (15 hr half-life) and ${ }^{50} \mathrm{Mn}$ (2.6 hr half-life). Analyses for these two elements provides useful data for geologic source identification since the sodium content may differ by more than a factor of two and the manganese by a factor of ten or more. Equally important is that the sodium and manganese contents for a specific geologic source each exhibit a range which is probably not greater than 1.35. The analysis for these two elements serves principally to eliminate most geologic sources as quarry sites for a given artifact and thus reduces considerably the number of analyses for additional elements which would be needed for final identification of the geologic origin of an artifact. Using precise but time-consuming activation analysis techniques it would be possible to determine the $\mathrm{Na}$ and $\mathrm{Mn}$ contents to better than $\pm 2 \%$. We have simplified the analysis procedure in order to automate the analysis and permit examining over 10,000 samples a year. As a result, our data are valid to about $\pm 5 \%$. The procedure involves taking a series of measurements of the activity of the samples over a period of 22 hours and, as indicated in figure 1 , resolving these radioactivity decay data into their ${ }^{24} \mathrm{Na}$ and ${ }^{58} \mathrm{Mn}$ components.

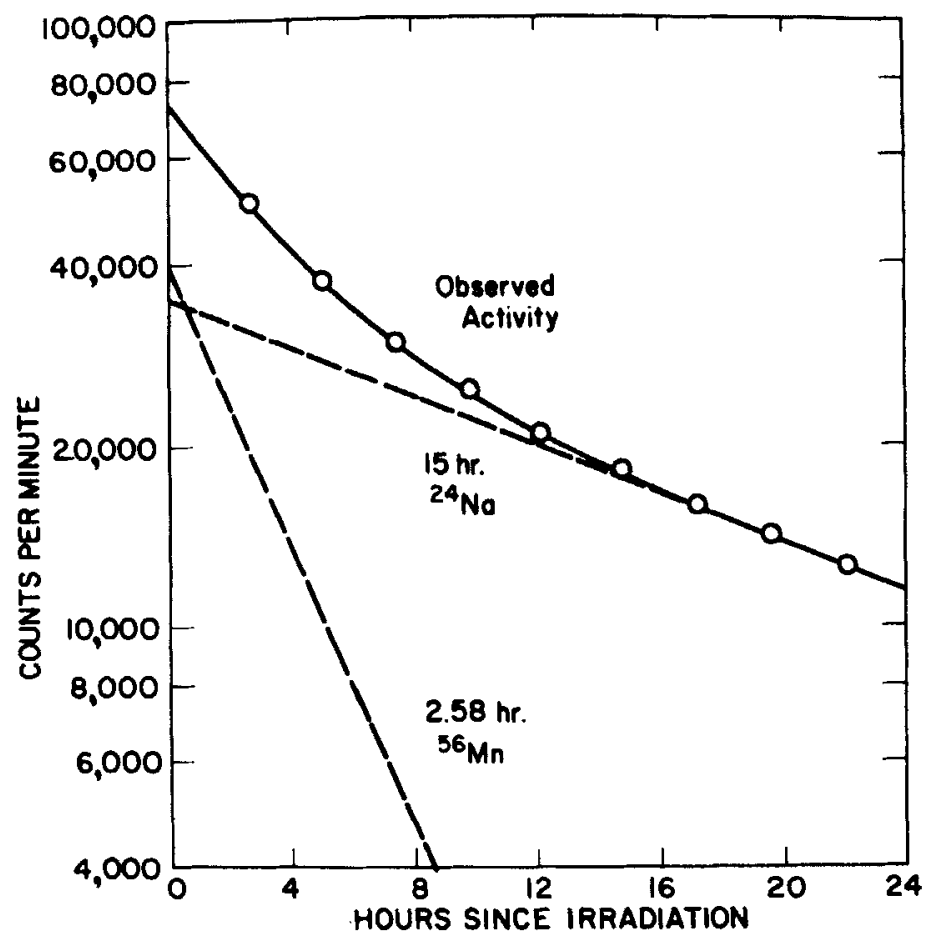

FIG. 1. Resolution of the radioactivity decay data for an obsidlian sample into its ${ }^{24} \mathbf{N a}$ and ${ }^{56} \mathrm{Mn}$ decay components. 


\section{ANALYSIS PROCEDURE}

An automatic data-acquisition system was assembled. It consists of an automatic sample changer (Nuclear-Chicago Corp., Model 1085) having a capacity to handle 100 samples, a $2^{\prime \prime} \times 2^{\prime \prime}$ well-type $\mathrm{NaI}$ (T1) scintillation detector (Harshaw Chemical Co., Model 8SF8), a single-channel analyser (Baird-Atomic Co., Model 530 Spectrometer*) and a printer (Baird-Atomic Co., Model 620)**.

The overall system was constructed to provide maximum versatility so that analyses for elements other than ${ }^{24} \mathrm{Na}$ and ${ }^{56} \mathrm{Mn}$ could be handled with only slight modification.

Samples, having an average weight of about $30 \mathrm{mg}$, and chemical standards, having approximately the same $\mathrm{Na}$ and $\mathrm{Mn}$ content as the samples, were individually sealed in $1^{\prime \prime}$ polyethylene tubing and irradiated together with some empty polyethylene tubing for 40 seconds in a pneumatic tube facility of The University of Michigan two-megawatt nuclear reactor. The samples, standards, and empty holders (which were analysed and treated as background counts) were placed in test-tubes and automatically analysed by taking one-minute counts during the period 2 to 24 hours following the end of the irradiation. The sample-changing time was $27 \mathrm{sec}$, resulting in a time-lapse of $2 \mathrm{hr}$ and $25 \mathrm{~min}$ between successive counts of any sample. As a result, a total of 9 individual counts were taken for each sample during the 22 hour analysis period.

Because the sample-changing time was very reproducible, it was not necessary to incorporate in the system a continually running automatic-readout electronic clock to indicate the time at which each count was taken. It was only necessary to note the time of the day at which the first count of the first cycle began and the time of the day at which the first count of the tenth cycle was started. The computer was then provided with the elapsed time required for a single cycle and was instructed to determine the time of the day at which each count was recorded.

It was necessary to use a single-channel analyser since the manganese content of obsidian is so low that comparable ${ }^{5} \mathrm{Mn}-{ }^{24} \mathrm{Na}$ counting statistics would not be obtained unless some of the ${ }^{24} \mathrm{Na}$ activity was suppressed. To accomplish this, the energy "window" of the single-channel analyser was centered on the $0.845 \mathrm{MeV}$ gamma-ray peak of ${ }^{30} \mathrm{Mn}$ and included only the energy range 0.76 to $0.93 \mathrm{MeV}$.

The counts recorded for each sample were automatically printed on paper tape as the changer advanced to the next sample.

The computer was provided with the radioactivity counts and additional data specific to each run. These latter data consisted of: (a) cur code-number identification for each sample, standard, or background, (b) the weight of each sample or standard, (c) the $\mathrm{Na}$ and $\mathrm{Mn}$ contents of the standards, (d) the half-lives of the isotopes being examined, (e) the time of day at which the first count of the first cycle began, (f) the elapsed time required per cycle, and (g) the time of day at which the $\mathrm{Na}$ and $\mathrm{Mn}$ activity was to be calculated (generally $12 \mathrm{hrs}$ from the end of the irradiation).

* Only obvious interfacing which was extremely simple to construct and install was needed to connect the sample changer to the spectrometer; the Model 530 already has a built-in 1 - 100 sample number generator.

* The necessary circuitry is being constructed so that a paper-punch unit (Teletype Corp., Model 33 ASR) could be used instead of the printer. The use of this punch would eliminate the need to punch the data manually on IBM cards in order to have the data available in a computer-compatible form. 
The computer sorted the decay data according to sample number, subtracted background, resolved the data for each sample and standard into its ${ }^{24} \mathrm{Na}$ and ${ }^{58} \mathrm{Mn}$ components using the method of least squares, and calculated the ${ }^{24} \mathrm{Na}$ and ${ }^{80} \mathrm{Mn}$ activities at the defined reference time. (As noted below, samples 2-50 and 51-100 were irradiated in two separate groups; computer analyses, therefore, were performed in two groups.) The "goodness-of-fit" of the ${ }^{21} \mathrm{Na}$ and ${ }^{86} \mathrm{Mn}$ components was computed from the variance of the fitted curve. If any point(s) differed from the curve by a statistically significant amount, the point(s) was rejected and a new fit performed.

The activity $\left(\mathrm{A}^{\circ}\right)$ per $\mathrm{mg}$ sample per \% (Na or $\mathrm{Mn}$ ) was calculated for each of the standards. The ${ }^{24} \mathrm{Na}$ and ${ }^{56} \mathrm{Mn} \mathrm{A}^{\circ} / \mathrm{mg}-\%$ data for the standards were then averaged, standard deviations (of the mean) were calculated, and any data rejected which did not satisfy Chauvenet's criterion, in which case new means and standard deviations were calculated.

The ${ }^{24} \mathrm{Na}$ and ${ }^{58} \mathrm{Mn}$ activities per $\mathrm{mg}$ sample were then calculated for each sample and these quantities, with their associated "goodness-of-fit", were divided by the mean $\mathrm{A}^{\circ}\left({ }^{24} \mathrm{Na}\right.$ or $\left.{ }^{56} \mathrm{Mn}\right) / \mathrm{mg}-\%$ values of the standards to yield the percentage compositions of each sample.

The data print-out from the computer consisted of the individual activity input data for each sample, information on rejected data, the computed activities and percentages, and a summary sheet of the $\%$ compositions and the $\% \mathrm{Na} / \% \mathrm{Mn}$ ratio, each with its calculated uncertainty. A typical set of computer-output data

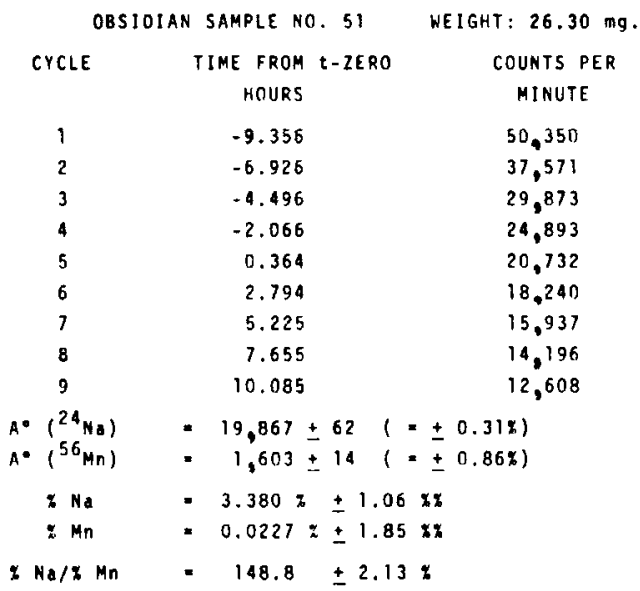

FIG. 2. Computer output for the decay data shown in figure 1.

is given in figure 2. For this set the average values of the five standards were found to be $\mathrm{A}^{\circ}\left({ }^{24} \mathrm{Na}\right) / \mathrm{mg}-\% \mathrm{Na}=223.5( \pm 1.02 \%)$ and $\mathrm{A}^{\circ}\left({ }^{58} \mathrm{Mn}\right) / \mathrm{mg}-\% \mathrm{Mn}=$ $2683( \pm 1.63 \%)$. As seen in figure 2 , the uncertainty in fitting the data for this sample is quite small, $\pm 0.31 \%$ and $\pm 0.86 \%$ for the two isotopes. This is typical of the individual data fits and is to some extent simply a reflection of the randomness of radioactivity decay; at 100,000 counts the uncertainty is $\left(10^{5}\right)^{\frac{1}{2}}= \pm 0.31 \%$; at 10,000 counts it is $\pm 1.00 \%$. The uncertainty in the $\% \mathrm{Na}$ and $\% \mathrm{Mn}$ values, however, is more a reflection of the standard deviation of the average $\mathrm{A} / \mathrm{mg}-\%$ values of the standards. This latter variation is discussed below. 
Although the computer curve-fitting procedure results in small uncertainties, especially when comparable levels of ${ }^{24} \mathrm{Na}$ and ${ }^{56} \mathrm{Mn}$ activities are involved, a major source of error can arise from the neutron irradiation procedure. Whenever a large bulk of material, such as 100 obsidian samples, is irradiated the neutron dose received by each sample will differ due to relative positioning, neutron attenuation by other samples, and variation in the fast- to thermal-neutron ratio in various positions of the irradiated capsule. Seven standards contained in these capsules usually exhibited a spread in $\mathrm{A}^{\circ} / \mathrm{mg}-\%$ values of up to $20-30 \%$ and an average value having a standard deviation of the order of $\pm 5 \%$.

To minimize these irradiation effects, the samples were divided into two groups, each having five standards. The capsules were irradiated separately for $10 \mathrm{sec}$, shaken to redistribute the samples in each capsule, irradiated again for $10 \mathrm{sec}$, shaken again, and the procedure repeated for a total accumulated irradiation time of $40 \mathrm{sec}$. Using this procedure, the spread in $\mathrm{A} / \mathrm{mg}-\%$ values of the standards was reduced to about $8-10 \%$ and the standard deviation to about $\pm 1 \%$.

Since it appeared desirable to maintain a minimum of five standards per capsule, it did not seem worthwhile to decrease further the total number of samples per capsule. Any remaining variations in the computed $\mathrm{Na}$ and $\mathrm{Mn}$ contents which resulted from irradiation effects were minimized by re-analysing the samples one or more times and averaging these $\mathrm{Na}$ and $\mathrm{Mn}$ percentage values. This was possible since the radioactivity in the samples and standards was almost completely dissipated in about one week.

Errors resulting from the positioning of samples within the scintillation detector appear to be minimal. Electronic variations and long- or short-term drifts in the detector or energy "window" were shown to be minor by counting each cycle as the first sample a long-lived standard: ${ }^{134} \mathrm{Cs}$ ( $1.7 \mathrm{yr}$ half-life). This particular isotope was chosen since the higher-energy gamma-ray peak associated with it $(0.80$ $\mathrm{MeV}$ ) was only partially contained in the energy "window". Hence, a slight change in detector or analyser response would have been seen as a large variation in the count-rate of this isotope. Evidence for these latter errors would also have been noted in the assignment of larger uncertainties in the resolution of the decay curves. As stated above, the computer fits were within the error limits expected from the count rates, suggesting that these latter sources of error are unimportant.

Occasionally, however, a "goodness-of-fit" larger than that expected was found. Invariably this resulted from a sample that was so large that its initial count-rate was high $(>500,000$ counts $/ \mathrm{min})$ and pulse-resolution or phototube-drift effects became important. It was desirable, therefore, to use for any given irradiation samples that were uniform in size and to adjust the irradiation time for sample batches in terms of their average weights.

Replicate determinations of the $\mathrm{Na}$ and $\mathrm{Mn}$ contents of a given sample invariably showed a range of $10 \%$ or less. The average of such replicate assays resulted in an overall uncertainty of better than $\pm 5 \%$.

\section{PRESENCE OF OTHER ISOTOPES}

Computer-simulated decay data were created in order to determine what effect the presence of small amounts of ${ }^{38} \mathrm{Cl}\left(37.5 \mathrm{~min}\right.$ half-life) or ${ }^{140} \mathrm{La}(40 \mathrm{hr}$ half-life) would have on the resolution of the decay data if the data were treated as if only ${ }^{24} \mathrm{Na}$ and ${ }^{56} \mathrm{Mn}$ were present. It was assumed that at $\mathrm{t}=0$ a sample contains 
200,000 counts/min of ${ }^{56} \mathrm{Mn}, 50,000 \mathrm{count} / \mathrm{min}$ of ${ }^{24} \mathrm{Na}$, and possibly 5,000 counts/ min of ${ }^{38} \mathrm{Cl}$ and/or 1,000 counts/min of ${ }^{1 / 1}$ "La. The precise activity of each nuclide was calculated at two-hour intervals and a slight statistical ffuctuation characteristic of radioactivity decay measurements was introduced to each value. For example, the exact ${ }^{24} \mathrm{Na}+{ }^{56} \mathrm{Mn}$ activity at $\mathrm{t}=24 \mathrm{hrs}$ was 16,884 whereas the randomized value was 17,033 .

Some of the computer-resolved data obtained using the computer program described in the preceding section are given in Table 1. These calculated activities and the computer-determined uncertainty were based on the assumption that only

\section{TABLE I}

COMPUTER CALCULATID ACTIVITIES AT TIME $=0$ USING COMPUTER RANDOMIZED SYNTHETIC DATA ${ }^{\mathrm{a}}$

$\begin{array}{lcccc}\begin{array}{c}\text { Activities } \\ \text { Present }\end{array} & { }^{56} \mathrm{Mn} & \begin{array}{c}\text { Computer Calculated } \\ \pm \%\end{array} & \begin{array}{c}\text { Activity } \\ 24 \mathrm{Na}\end{array} & \pm \% \\ \mathrm{Na}+\mathrm{Mn} & 199,625 & 0.20 & 50,084 & 0.35 \\ \mathrm{Na}+\mathrm{Mn}+\mathrm{La} & 199,216 & 0.13 & 51,356 & 0.23 \\ \mathrm{Na}+\mathrm{Mn}+\mathrm{Cl} & 201,967 & 0.30 & 49,509 & 0.56 \\ \mathrm{Na}+\mathrm{Mn}+\mathrm{Cl}+\mathrm{La} & 201,608 & 0.20 & 51,333 & 0.37\end{array}$

a Exact activities used at $t=0$ were: $200,000{ }^{56} \mathrm{Mn} 50,000{ }^{24} \mathrm{Na}, 5,000{ }^{38} \mathrm{Cl}$, and 1,000

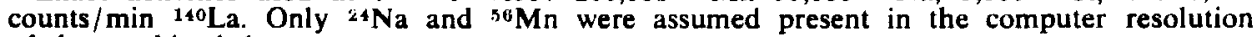
of the combined data.

${ }^{24} \mathrm{Na}$ and ${ }^{36} \mathrm{Mn}$ were present in each sample. From these data it is seen that the introduction of these small amounts of ${ }^{110} \mathrm{La}$ and/or ${ }^{38} \mathrm{Cl}$ activity does not markedly effect the decay-curve fitting process. A short-lived activity $\left({ }^{38} \mathrm{Cl}\right)$ is added preferentially to the ${ }^{36} \mathrm{Mn}$ whereas a long-lived activity $\left({ }^{140} \mathrm{La}\right)$ is added mainly to the ${ }^{24} \mathrm{Na}$. Thus, if a sample contained small amounts of impurity activities these would not be detected in terms of the standard deviations of the fits. These extra activities, however, would appear as part of the ${ }^{24} \mathrm{Na}$ and ${ }^{54} \mathrm{Mn}$ calculated activities and thus result in calculated $\mathrm{Na}$ and $\mathrm{Mn}$ contents that were too high.

It is important to note that the amount of additional activity in an artifact would be equal to the amount of additional activity in the geologic source material from which the artifact was constructed. Therefore, any error in the $\mathrm{Na}$ and $\mathrm{Mn}$ analyses would be of the same magnitude for both the artifact and its geologic source sample.

Using published data on the chemical composition of obsidian it was possible to estimate that the amount of activity to be expected from nuclides such as ${ }^{38} \mathrm{Cl},{ }^{140} \mathrm{La},{ }^{42} \mathrm{~K}$ and ${ }^{4}{ }^{8} \mathrm{Sc}$ would be less than $1-2 \%$ of the combined ${ }^{24} \mathrm{Na}+{ }^{56} \mathrm{Mn}$ activity. These additional minor activities would be difficult to detect in the presence of the large amount of ${ }^{24} \mathrm{Na}$ and ${ }^{56} \mathrm{Mn}$ and randomly selected irradiated obsidian samples, when analysed by gamma-ray spectrometry. showed only ${ }^{24} \mathrm{Na}$ and ${ }^{56} \mathrm{Mn}$ peaks. As an additional check of the decay-curve method of $\mathrm{Na}-\mathrm{Mn}$ analysis data from the gamma-ray spectrometry measurements on selected samples were used to compute the $\mathrm{Na}$ and $\mathrm{Mn}$ contents; the calculated $\mathrm{Na}$ and $\mathrm{Mn}$ values agreed with those obtained by the sample-changer decay-curve method.

\section{GEOLOGIC-SOURCE IDENTIFICATION}

To date we have determined the $\mathrm{Na}$ and $\mathrm{Mn}$ contents of over 1900 obsidian samples. In order to obtain highly reliable data each sample was irradiated and 
analysed an average of five times and the individual $\mathrm{Na}$ and $\mathrm{Mn}$ data averaged. From these data it was apparent that the range in composition of these two elements for a geologic source is not more than 1.35. Some of these data for sources in the Western United States are given in figure 3.

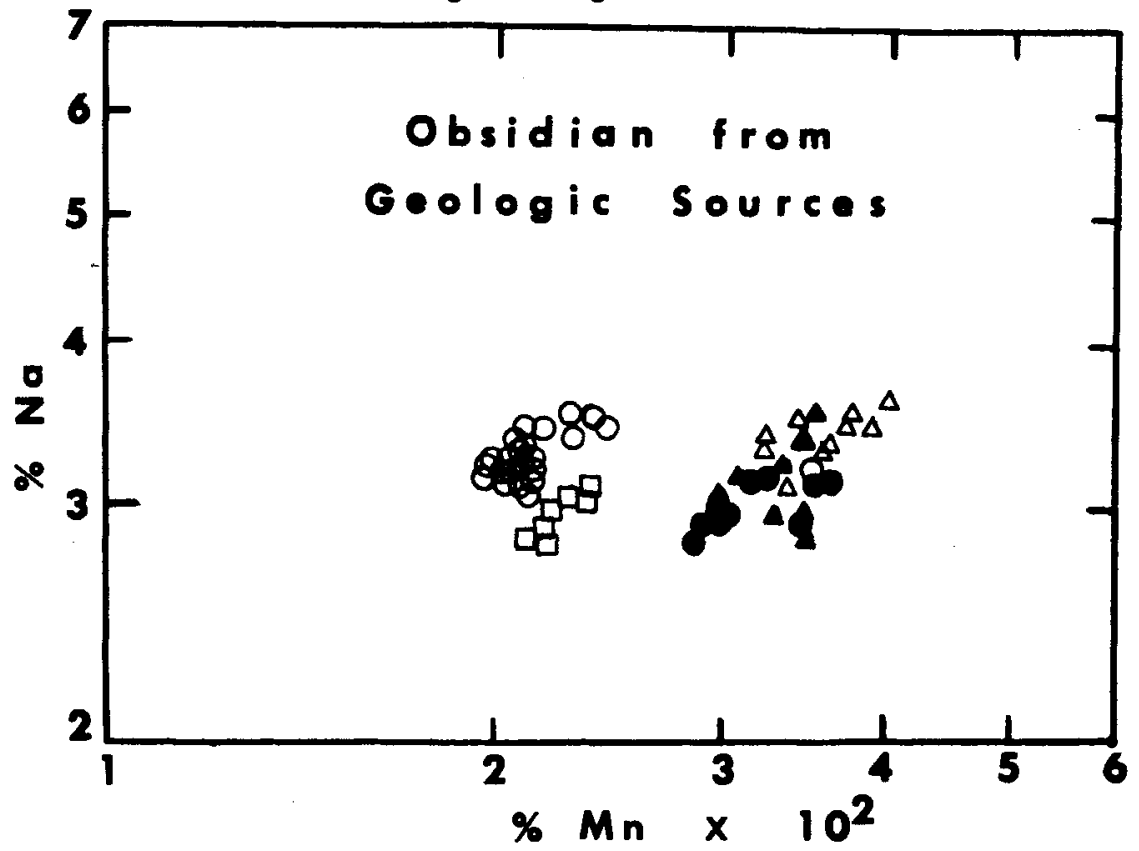

FIG. 3. Data for the $\mathrm{Na}$ and $\mathrm{Mn}$ contents of a number of geologic sources of obsidian in the Western United States. Obsidian Cliff, Yellowstone National Park: O; Oneida Perlite, Idaho: $\square$; Mono Lake, California: $\triangle$; Montana : $\Delta$; Wyoming:

For the past 120 years anthropologists have been speculating about the source or sources of the obsidian that was used by the Hopewell Indians (a cultural group that inhabited Ohio, Indiana, Illinois, and parts of Michigan and Wisconsin during the period 300 B.C. -500 A.D.). The cbsidian is found in the form of projectile points in the Hopewell burial mounds but the closest geologic sources of obsidian are in the Western United States, Mexico, and in Alaska. The $\mathrm{Na}$ and $\mathrm{Mn}$ contents of the Hopewell obsidian artifacts are given in figure 4. Of the many North American obsidian sources tested only three have $\mathrm{Na}$ and $\mathrm{Mn}$ contents corresponding to the cluster of Hopewell obsidian data on the left of figure 4. These sources are Obsidian Cliff in Yellowstone National Park, a source in Idaho (both shown in figure 3), and a source in Mexico. The smaller group of samples on the right of figure 4 have $\mathrm{Na}$ and $\mathrm{Mn}$ contents similar to those found in a number of sources, including those shown in figure 3.

The analyses for $\mathrm{Na}$ and $\mathrm{Mn}$, therefore, reduces considerably the number of geologic sources that must be considered in attempting to identify the geologic source of the Hopewell obsidian. A final identification of source was based on analyses of additional elements in obsidian. Samples were irradiated for 24 hours in the reactor and it was possible to detect ${ }^{50} \mathrm{Fe},{ }^{153} \mathrm{Sm},{ }^{140} \mathrm{La},{ }^{40} \mathrm{Sc},{ }^{88} \mathrm{Rb}$ and about 10 or more other nuclides. Because of the large number of gamma-rays emitted by these samples, it was necessary to analyse them by gamma-ray spectrometry. 


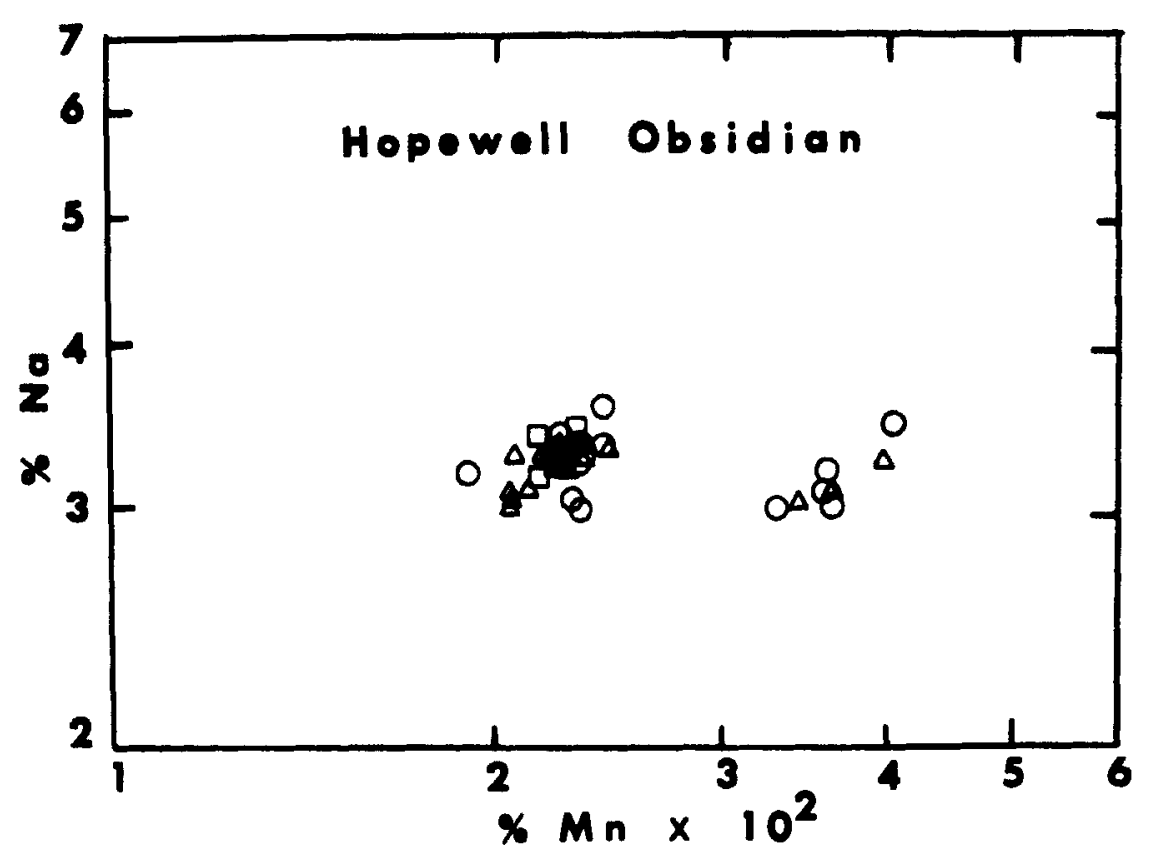

Fio. 4. Date for the $\mathrm{Na}$ and $\mathrm{Mn}$ contents of obsidian artifacts found in Hopewell Indian burial mounds. Site of mound, Illinois: $O$ : Ohio: $\Delta$; Michigan: $\square$.

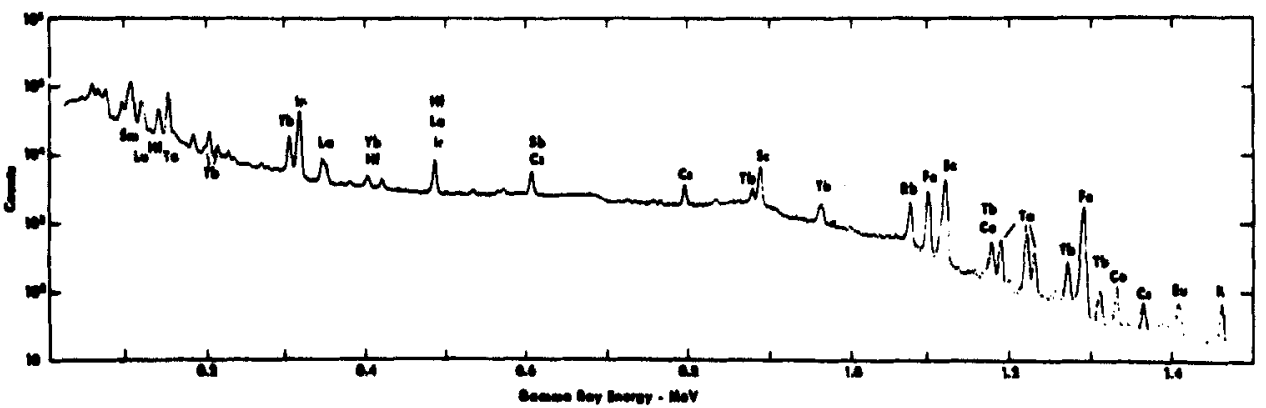

Fio. 5. Gamma-ray spectrum of a ample of obsidian from Obsidian Cliff in Yellowatone National Park, taken 15 days after a 24 hr. neutron irradiation.

A gamma-ray spectrum for obsidian from Obsidian Cliff in Yellowstone National Park is shown in figure 5. From the size of the peaks for Sm, Sc, Rb, Fe, and La compared with the same peaks for spectra taken on chemical standards irradiated together with the obsidian samples it was possible to calculate the amount of each of these elements present in the samples. It was also found that the content of these five elements in the Hopewell obsidian on the left of figure 4 agreed with the Obsidian Cliff sample. Further, by superimposing the Hopewell and Obsidian Clif spectra the remaining peaks, which are the result of at least 10 additional elements, also visually showed a correspondence. Equally important, spectra of irradiated samples from other sources having the same $\mathrm{Na}$ and $\mathrm{Mn}$ 
contents as the Hopewell obsidian showed statistically important differences in the amounts of some of the elements.

It was also determined that the Hopewell samples on the right of figure 4 have $\mathrm{Sm}, \mathrm{Sc}, \mathrm{Rb}, \mathrm{Fe}$, and $\mathrm{La}$ contents that correspond to obsidian from another geologic flow in Yellowstone National Park but differ from that present in other sources having similar $\mathrm{Na}$ and $\mathrm{Mn}$ contents. These and additional data for obsidian artifacts and geologic source material from many parts of the world will be discussed extensively in separate publications.

The method of $\mathrm{Na}$ and $\mathrm{Mn}$ analyses described here assists materially in the identification of the geologic source of an obsidian artifact. Because of the simplicity of the semi-automated analysis procedure it is possible to handle the large number of samples needed in order to obtain statistically significant data. Although obsidian analyses were discussed in order to illustrate the use of this procedure, it is not limited to this particular mineral. Clay pottery and flint, when irradiated for about a minute in a reactor, also emit principally ${ }^{24} \mathrm{Na}$ and ${ }^{50} \mathrm{Mn}$ gamma-rays during the period $2-24$ hours following the irradiation and this analysis procedure can also be used for preliminary studies of artifacts of these types.

A slight modification, however, has to be made in the case of flint; the $\mathrm{Na}$ content of flint is only about $10 \%$ of that of obsidian. As a result, it is not necessary to suppress the ${ }^{24} \mathrm{Na}$ activity in order to obtain comparable ${ }^{24} \mathrm{Na}-{ }^{56} \mathrm{Mn}$ counting statistics. In the flint analyses we have performed, we usually set the energy "window" of the single-channel analyser to detect all radiation above 0.7 $\mathrm{MeV}$.

Long-term ( $24 \mathrm{hr})$ irradiations of pottery and flint yield spectra similar to that of figure 5 although the relative amounts of some of the peaks can be markedly different from that of figure 5 . We should remark, however, that determining the geologic source of a flint artifact is not as simple as for an obsidian artifact. Because flint is a sedimentary mineral the range of trace elements in flint from a single geologic source is frequently much larger than that of obsidian. Therefore, a much greater overlapping in composition is found when different sources are compared. We are presently analysing various flint samples to determine the ranges in composition which exist in single geologic source areas.

\section{ACKNOWLEDGMENTS}

Professor James C. Griffin originally suggested the study of obsidian by neutron activation analysis and he and his colleagues throughout the world provided many of the samples. A number of students, and Gary Wright in particular, assisted in organizing and preparing the samples for analysis. The University of MichiganMemorial Phoenix Project and the National Science Foundation provided the financial assistance for these studies. 
Metal objects and coins:

BIBLIOGRAPHY

Aitken, M. J., Emeleus, V. M., Hall, E. T., and Kraay, C. M., 1962, "Conf. Radioisotopes in the Physical Sciences and Industry", Vol. II, p. 263, Intl. Atomic Energy Agency, Vienna. Ambrosino, G., and Pindrus, P., 1963, Rev. Metall., 50, 136, Paris.

Bacharach, J., and Gordus, A. A., 1968, J. Econ. Soc. Hist. Orient, in press.

Bluyssen, H., and Smith, P. H. B., 1962, Archaeometry, 5, 113.

Das, H. A., and Zonderhuis, J., 1965, Chem. Weekblad, 61 (18), 215.

Emeleus, V. M., 1958, Archaeometry, 1, 6.

Kraay, C. M., 1959, Archaeometry, 2, 1.

Kusaka, Y., 1959, Japan Analyst, 8, 111.

Meloni, S., and Maxia, V., 1962, Gazz. Chim. Ital., 92, 1432.

Ravetz, A., 1963, Archaeometry, 6, 46.

Thompson, M., 1960, Archaeometry, 3, 10.

Wyttenbach, A., and Hermann, H., 1966, Archaeometry, 9, 139.

Zuber, I. K., 1965, At. Energy Comm., Istanbul, Report No. CNAEM-21, part 1, 1966, CNAEM-35, part 2.

Ceramics and pottery:

Bennyhoff, J. A., and Heizer, R. F., 1965, Am. Antiquity, 30, 348.

Emeleus, V. M., and Simpson, G., 1960, Nature, 185, 196.

Johnson, R. A., and Stross, F. H., 1965, Am. Antiquity, 30, 345.

Sayre, E. V., 1958, Seminar Proc. on Application of Science in Examination of Works of Art, Research Lab. of Fine Arts, Boston, 153.

Sayre, E. V., 1962, Trans. Am. Nuclear Soc., 5, 283.

Sayre, E. V., 1963, Ann. Rev. Nuclear Science, 13, 145.

Sayre, E. V., and Dodson, R. W., 1957, Am. J. Arch., 61, 35.

Sayre, E. V., Murrenhoff, A., and Weick, C. F., 1958. Brookhaven Natl. Lab. Report (Upton, New York), BNL-508 (T-122)

Simpleson, G., 1960, Archaeometry. 3, 20. 